\title{
HIDUNG ELEKTRONIK BERBASIS SENSOR GAS MOS UNTUK KARAKTERISASI KEMATANGAN BUAH KELAPA SAWIT
}

\section{ELECTRONIC NOSE BASED ON MOS GAS SENSOR TO CHARACTERIZE RIPENESS OF OIL PALM FRESH FRUITS}

\author{
Minarni Shiddiq $^{1}$, Lentina Br. Sitohang ${ }^{1}$, Ikhsan Rahman Husein ${ }^{1}$, Sinta Afria Ningsih ${ }^{1}$, \\ Sri Hermonica ${ }^{1}$, Annisa Fadlilah ${ }^{1}$ \\ ${ }^{1}$ Jurusan Fisika, FMIPA, Universitas Riau \\ ${ }^{\otimes}$ Komunikasi Penulis, email: minarni.shiddiq@lecturer.unri.ac.id \\ DOI:http://dx.doi.org/10.23960/jtep-lv10i2.170-182
}

Naskah ini diterima pada 28 Desember 2020; revisi pada 4 April 2021; disetujui untuk dipublikasikan pada 6 April 2021

\begin{abstract}
The ripeness of oil palm fruits is one of the key factors for crude palm oil qualities. Recently, electronic nose systems have been developed intensively for fruit quality assessment which relates odors to ripeness levels. This study developed an electronic nose system to characterize the ripeness levels of oil palm fruits using output voltage of each sensor and fruit hardness. The system consisted of a sensor chamber and a sample chamber. The sensor chamber consisted of eight MOS gas sensor modules of MQ series. Samples were oil palm fruits taken from oil palm fresh fruit bunches (FFB) which were previously categorized traditionally into unripe, ripe, over ripe, peeled and put into the sample chamber. Some of the fruits were also used for hardness measurement. To quantify the output voltages for each sensor, integrated trapezoid areas were calculated and related to the fruit hardness values. The results showed a significant voltage difference of each sensor for the three ripeness levels. Only four out of eight sensors showed significantly higher voltages. Three sensors which can significantly differentiate the ripeness levels are MQ3, MQ5, and MQ135 which MQ135 is the best. This shows that the electronic nose is potential for oil palm fruits.
\end{abstract}

Keywords: electronic nose, fruit hardness, MOS gas sensor, oil palm fruit, ripeness

\begin{abstract}
ABSTRAK
Kematangan buah kelapa sawit merupakan salah satu faktor penentu kualitas dari crude palm oil (CPO). Saat ini, sistem hidung elektronik telah banyak dikembangkan untuk mengevaluasi kualitas buah dengan menghubungkan aroma buah dengan tingkat kematangan. Pada penelitian ini, sistem hidung elektronik dikembangkan untuk mengkarakterisasi tingkat kematangan buah kelapa sawit menggunakan tegangan keluaran setiap sensor dan kekerasan buah. Sistem tersebut terdiri dari ruang sensor dan ruang sampel. Ruang sensor terdiri dari 8 modul sensor gas MOS dari seri MQ. Sampel adalah buah-buah kelapa sawit yang dicabut dari tandan-tandan sawit yang terdiri dari tiga tingkat kematangan yaitu mentah, matang, lewat matang yang sebelumnya dikategorikan secara tradisional, selanjutnya dikupas dan dimasukkan ke dalam ruang sampel. Beberapa buah juga diambil untuk pengukuran kekerasan buah. Untuk mengkuantisasi tegangan yang berubah terhadap waktu, integrasi luas area dibawah kurva dihitung dan dihubungkan dengan nilai kekerasan buah. Hasil menunjukkan perbedaan yang signifikan dari tegangan keluaran dari setiap sensor untuk setiap tingkat kematangan. Empat sensor menunjukkan tegangan keluaran yang paling tinggi. Tiga sensor yang dapat membedakan tingkat kematangan buah sawit adalah MQ3, MQ5, dan MQ135, dimana MQ135 adalah yang terbaik. Hal ini menunjukkan bahwa hidung elektronik potensial digunakan untuk buah kelapa sawit.
\end{abstract}

Kata Kunci: buah kelapa sawit, gas sensor MOS, hidung elektronik, kekerasan buah, kematangan 


\section{PENDAHULUAN}

Hidung elektronik merupakan sistem elektronik pendeteksi aroma yang menirukan prinsip kerja hidung manusia yang mempunyai reseptorreseptor pengidentifikasi aroma. Reseptorreseptor pengidentifikasi aroma pada hidung elektronik adalah sensor-sensor gas yang disusun dan disebut larik sensor. Setiap hidung elektronik yang dibuat untuk sebuah tujuan mempunyai keunikan karena melibatkan sensor-sensor gas berbeda dan jenis aroma yang dideteksi juga berbeda. Saat ini beberapa jenis sensor berbasis metal oxide semiconductor (MOS) seperti seri Figaro TGS dan MQ tersedia secara komersial dengan harga yang relatif murah sehingga membangun sistem hidung elektronik yang ekonomis dimungkinkan. Sensor-sensor seri TGS dan MQ ini telah tersedia dalam bentuk modul sehingga sistem hidung elektronik yang dibangun menjadi lebih sederhana.

Sistem hidung elektronik telah banyak dikembangkan untuk bidang pertanian khususnya untuk evaluasi kualitas buah dan sayuran berdasarkan aroma yang dihasilkan buah dan sayuran tersebut. Hidung elektronik telah digunakan untuk memonitor tingkat kematangan buah (Baietto et al., 2015), mengklasifikasi aroma dari 4 jenis buah (Adak dan Yumusak, 2016), dan untuk mengkarakterisasi pola aroma salak pondoh (Lelono dan Chairiawan, 2013). Metode hidung elektronik juga dapat dikombinasikan dengan metode lainnya sehingga proses pendeteksian kualitas buah lebih optimal.. Kombinasi hidung elektronik dengan sistem lainnya diantaranya adalah kombinasi hidung elektronik dan sensor akustik untuk klasifikasi buah mangga (Zakaria et al., 2012), gabungan hidung elektronik dan sistem kamera untuk buah pisang (Chen et al., 2018), dan gabungan spektroskopi NIR dan hidung elektronik untuk prediksi waktu buah persik mulai busuk (Huang et al., 2017). Hidung elektronik yang dikombinasikan dengan metode Gas Chromatography-mass Spectrometry (GCMS) dapat digunakan untuk mengkarakterisasi sifat internal buah seperti kadar gula, asam lemak, asam amino, komposisi gas volatil pada beberapa tingkat kematangan (Song et al., 2019).
Tanaman kelapa sawit merupakan tanaman yang menghasilkan buah kelapa sawit yang tersusun dalam bentuk tandan yang disebut tandan buah segar (TBS). Saat ini, industri kelapa sawit merupakan industri penopang ekonomi Indonesia dalam menghasilkan crude palm oil (CPO). Keberlanjutan industri ini memerlukan terobosan teknologi seperti otomasi menggunakan sensor-sensor elektronik untuk evaluasi dan prediksi kualitas TBS sebelum diproses untuk menghasilkan CPO. Sistem sensor ini dapat menjadi bagian dalam mesin sortasi dan penentuan mutu TBS dan dapat juga digunakan dalam penentuan tingkat kedewasaan (maturity) TBS sebelum dipanen. Kualitas CPO ditentukan sebagian besar dari kualitas TBS yang memasuki pabrik kelapa sawit, salah satunya dari tingkat kematangannya. Tingkat kematangan berhubungan dengan kadar minyak dan kadar asam lemak bebas (ALB). Secara umum, kandungan Asam Lemak Bebas (ALB) pada CPO Indonesia lebih besar dari standar ALB yang seharusnya kecil dari 5\% (Hudori, 2016). Kualitas TBS kelapa sawit terbaik yaitu buah yang memiliki kandungan minyak tertinggi dan kadar ALB terendah (Razali et al., 2012).

Penentuan tingkat kematangan TBS kelapa sawit secara modern saat ini telah banyak dikembangkan untuk menggantikan metode tradisional dan manual. Metode manual berarti masih menggunakan tenaga manusia sementara metode tradisional masih mengandalkan pemanen atau mandor berpengalaman dengan penglihatan mata yang berdasarkan jumlah buah yang lepas dan perubahan warna buah. Metodemetode nondestruktif telah dikembangkan untuk menggantikan metode tradisional agar proses sortasi TBS dapat dilaksanakan secara cepat, otomatis, ekonomis, dan akurat. Metode penentuan mutu TBS yang telah diusulkan pada umumnya mengaplikasikan metode pencitraan dan pengolahan citra TBS yang dihubungkan pada sifat fisika dan kimia buah seperti penggunaan warna kulit buah untuk memprediksi kadar minyak TBS kelapa sawit (Sunikumar dan Babu, 2013). Citra TBS yang diperoleh dengan kamera CCD dan diolah menggunakan perangkat lunak untuk mengidentifikasi perbedaan dari tingkat 
kematangannya juga telah dilakukan (Fadilah dan Saleh, 2012). Metode Pencitraan fluoresensi dengan cahaya laser sebagai sumber cahaya juga diusulkan untuk penentuan kematangan TBS (Ishak et al., 2019). Pencitraan termal juga telah diusulkan untuk prediksi tingkat kematangan TBS kelapa sawit (Zolfagharnassab et al., 2017). Sensor elektronik juga telah banyak digunakan untuk buah kelapa sawit seperti probe optikyang terdiri dari laser dioda dan fotodioda (Sari et al., 2019) dan sensor optik (Utom et al., 2019). Metode lainnya adalah metode ultrasonik (Suwannarat et al., 2012) dan metode sensor kelembaban dengan gelombang mikro (Yeow et al., 2010).

Hidung elektronik telah banyak dikembangkan untuk berbagai jenis buah namun belum digunakan sepenuhnya untuk buah kelapa sawit khususnya untuk evaluasi tingkat kematangan TBS kelapa sawit berdasarkan aroma buah. Buah kelapa sawit dapat menghasilkan dua jenis minyak yaitu crude palm oil (CPO) atau minyak sawit merah yang berasal dari lapisan mesokarp dan palm kernel oil (PKO) yang berasal dari lapisan endosperm. PKO sebagian besar mengandung asam laurat, sedangkan CPO mengandung asam lemak (fatty acids) yang terdiri dari asam palmitat dan asam oleat (Dussert et al., 2013). Komposisi kimia dari minyak sawit adalah $50 \%$ asam lemak jenuh, dan hampir $50 \%$ asam lemak tak jenuh. Minyak sawit mengandung sebagian besar asam palmitat, diikuti dengan kandungan asam oleat dan linoleat yang cukup signifikan (Koushki et al., 2015). Aroma yang berasal dari komponen volatil jenis asam ini (Kuntom et al., 1989) dapat digunakan pada hidung elektronik sebagai prekursor tingkat kematangan buah.

Pada penelitian ini, sebuah sistem hidung elektronik dikembangkan untuk mengkarakterisasi tingkat kematangan buah kelapa sawit setelah dipanen berdasarkan nilai tegangan keluaran setiap sensor dan nilai kekerasan buah. Metode ini potensial digunakan karena buah kelapa sawit mengeluarkan aroma atau bau yang disebabkan zat kimia yang terkandung di dalam buahnya. Bagaimana sensitivitas setiap sensor terhadap bau yang disebabkan minyak sawit ini dan hubungannya dengan nilai tegangan keluaran setiap sensor di analisa. Tingkat kekerasan buah kelapa sawit diukur menggunakan sebuah penetrometer manual dan dihubungkan dengan tingkat kematangan buah. Nilai tegangan yang dihasilkan sensor dihubungkan dengan tingkat kekerasan buah untuk melihat potensial penggunaan sensor ini untuk deteksi kematangan buah kelapa sawit. Sistem ini selanjutnya akan dikembangkan lebih ringkas dan kompak sehingga dapat menjadi bagian dalam sistem sortir dan penentuan mutu TBS kelapa sawit saat panen atau setelah panen.

\section{BAHAN DAN METODE}

Pelaksanaan penelitian dilakukan dalam beberapa tahapan. Tahapan pertama adalah merancang dan membuat sistem hidung elektronik. Tahapan kedua adalah membuat program akuisisi data tegangan keluaran setiap sensor dan pengolahan data. Tahapan selanjutnya adalah membuat kotak sensor dan kotak sampel, kemudian menghubungkan keduanya menggunakan selang beserta perangkat lainnya. Setelah sistem dibuat dan program bekerja dengan baik, kinerja sistem divalidasi menggunakan keadaan tanpa sampel atau udara bersih dan dengan sampel. Selanjutnya, sampel buah-buah sawit dengan tiga tingkat kematangan di persiapkan, dikupas dan dimasukkan ke ruang sampel. Pada setiap jenis sampel, pengukuran tegangan keluaran dari setiap sensor gas yang digunakan dilakukan oleh program akuisisi data secara simultan dan ditampilkan sebagai kurva tegangan versus waktu, dan disimpan dalam bentuk format excel sehingga dapat dianalisa lebih lanjut. Tahapan selanjutnya adalah pengukuran kekerasan buah kelapa sawit yang diambil dari tandan yang sama dengan sampel untuk pengukuran dengan hidung elektronik. Tahapan terakhir adalah analisa data dari nilai tegangan dan hubungannya terhadap tingkat kematangan buah kelapa sawit. Tingkat kekerasan buah kelapa sawit digunakan untuk validasi pengklasifikasian tingkat kematangan oleh pemanen ketika sampel dipanen dan digunakan.

\subsection{Perancangan Sistem Hidung Elektronik} Alat dan bahan yang digunakan pada penelitian terdiri dari komponen elektronika seperti sensor 
gas, transistor (mosfet), kabel penghubung. Sensor yang digunakan sebanyak 8 buah (MQ 2, MQ3, MQ4, MQ5, MQ6, MQ8, MQ135, MQ136). Spesifikasi sensor yang digunakan dapat dilihat pada Tabel 1. Arduino Atmega 2560 digunakan sebagai pengendali mikro (microcontroller), selanjutnya catu daya, pompa vakum mini, selang oksigen, kipas mini sebagai penyebar gas dari sampel pada larik sensor dan laptop untuk menjalankan program akuisisi dan pengolahan data.

Blok diagram sistem hidung elektronik ditunjukkan pada Gambar 1. Sistem terdiri dari dua ruang yaitu ruang sampel dan ruang sensor (Lelono dan Chairiawan, 2013). Ruang sensor terbagi dalam dua bagian yaitu bagian sensor dan bagian Arduino. Delapan sensor yang digunakan adalah sensor seri MQ yang berupa modul yang disusun pada papan PCB sebagai larik sensor dan dihubungkan ke sumber tegangan dan kaki-kaki analog dari papan Arduino seperti ditunjukkan oleh Gambar 2a. Penggunaan modul sensor yang ditunjukkan oleh Gambar 2b dibanding dengan komponen sensor (stand alone) bertujuan untuk kemudahan dalam pembuatan sistem dan lebih sederhana. Modul sensor yang digunakan pada sistem hidung elektronik ini sudah mempunyai heater dan penguat Modul sensor ini mempunyai 4 kaki, kaki pertama sebagai A0 (analog output), kaki kedua untuk D0 (digital output), kaki ketiga sebagai Ground dan kaki keempat sebagai Vcc, hubungan ke catu daya. Semua kaki Vcc sensor dihubungkan menjadi paralel menggunakan jumper kabel penghubung, begitu juga untuk kaki ground sensor. Kaki analog sensor gas masing-masing dihubungkan pada Kaki analog Arduino dari A0 hingga A7 secara berurutan untuk sensor MQ2, MQ3, MQ4, MQ5, MQ6, MQ8, MQ135, MQ136. Keseluruhan modul sensor seri MQ membutuhkan tegangan dari luar disebabkan jumlah sensor yang banyak. Tegangan yang digunakan berasal dari catu daya yang arus dan tegangannya dapat divariasikan.

Ruang sensor dan Arduino berupa kotak akrilik dengan satu sekat sehingga kotak akrilik terbagi menjadi dua ruang. Kotak akrilik yang digunakan

Tabel 1. Spesifikasi Sensor Seri MQ yang Digunakan

\begin{tabular}{ccl}
\hline No. & Modul Number & \multicolumn{1}{c}{ Gas Target } \\
\hline 1. & MQ-2 & Gas methane, VOC \\
2 & MQ-3 & Gas Methane, Alkohol, VOC \\
3. & MQ-4 & $\mathrm{CH}_{4}$ dan Natural Gas \\
4. & MQ-5 & Gas Natural, Methane, Propana dan Iso-Butana \\
5. & MQ-6 & Gas LPG, Propane, Iso-Butane dan LNG \\
6. & MQ-8 & Gas Hidrogen \\
7. & MQ-135 & Gas Benzena, Alkohol dan $\mathrm{NH}_{3}$ \\
8. & MQ-136 & Gas $\mathrm{H}_{2} \mathrm{~S}$ \\
\hline
\end{tabular}

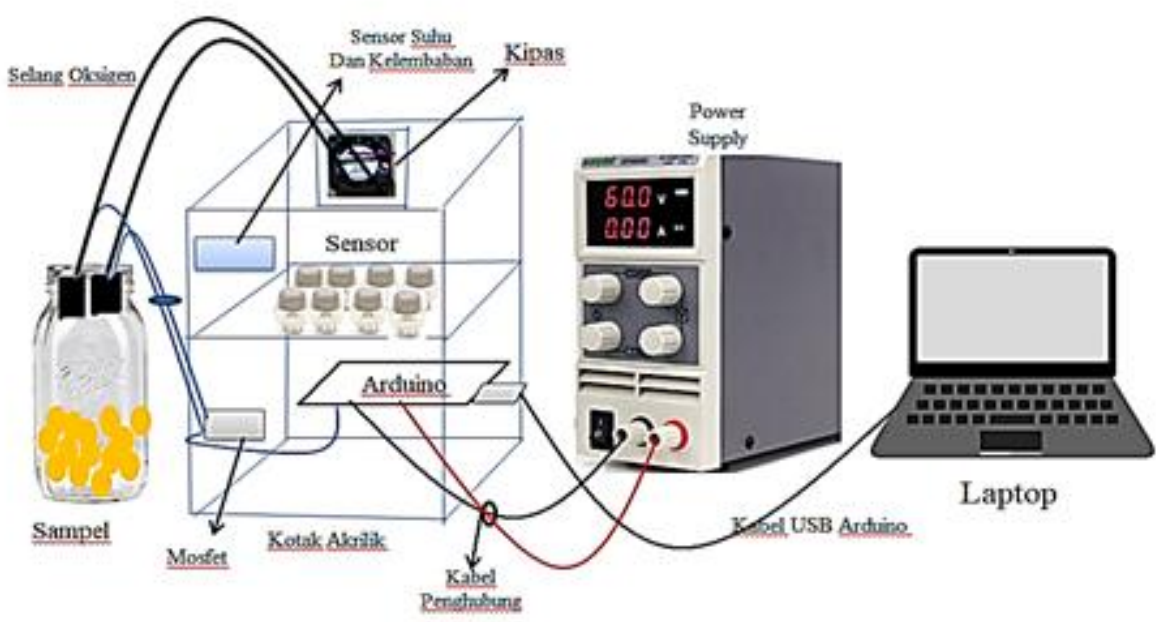

Gambar 1. Skema Hidung Elektronik untuk Buah Sawit 


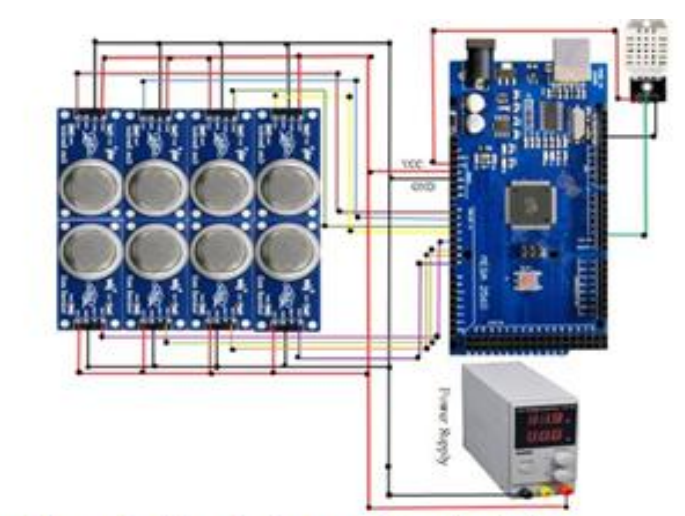

a. Koneksi Larik Sensor dan Arduino

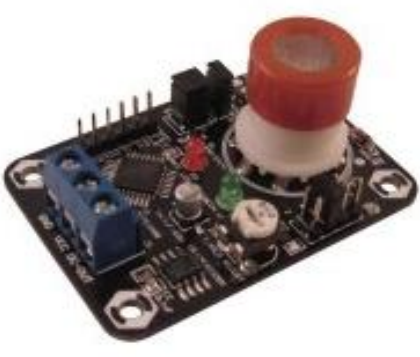

b. Modul Sensor

Gambar 2. Rangkaian Larik Sensor dan Arduino Atmega

mempunyai ukuran $12 \mathrm{~cm} \times 12 \mathrm{~cm}$ x $25 \mathrm{~cm}$. Kotak akrilik bagian atas sebagai tempat rangkaian modul sensor serta sensor suhu dan kelembaban DHT22 dengan kipas yang sudah direkatkan pada bagian atas ruang sensor untuk mempermudah penyebaran gas yang berasal dari sampel, sedangkan bagian bawah sebagai tempat mikrokontroler Arduino Atmega 2560, perkabelan dan rangkaian trigger menggunakan transistor LM317 sebagai penghubung pompa udara yang akan digunakan. Kotak akrilik dibuat menjadi 2 bagian agar ruang sensor tetap dalam keadaan vakum, tidak terganggu oleh komponen lain. Ruang sensor gas dibuat tidak terlalu besar agar gas dari buah sawit lebih mudah mengenai sensor sehingga pembacaan tegangan lebih stabil. Ruang sampel terbuat dari kaca dan kedap udara. Hal ini dilakukan, agar gas-gas aroma yang terdapat dalam buah kelapa sawit tetap stabil dan terjaga serta tidak terkontaminasi dengan gasgas yang berada di luar sampel. Wadah juga mempunyai pompa udara untuk mengeluarkan gas yang berasal dari sampel untuk pengukuran yang baru.

\subsection{Perancangan Program Akuisisi Data}

Sistem hidung elektronik yang dibangun terdiri dari perangkat keras (hardware) dan perangkat lunak (software) yang dapat menjalankan sistem akuisisi data. Perangkat keras dari sistem hidung elektronik meliputi sistem sensor, sistem kendali menggunakan mikrokontroler, dan sistem aliran fluida dari buah ke sistem sensor menggunakan pompa vakum mini dan kipas mini. Arduino IDE merupakan perangkat lunak yang digunakan untuk memprogram Arduino dimana kode ditulis dan di-compile kedalam papan Arduino. Kode yang ditulis berupa kode pengendali pompa menggunakan transistor, kode pembacaan nilai tegangan keluaran sensor, dan kode komunikasi serial Arduino agar data dapat diakuisisi. Perangkat lunak akuisisi data dibangun menggunakan Python yang merupakan bahasa pemrograman yang open source.

Bahasa pemrograman Python memiliki library yang dapat mempermudah pengembangan berbagai program komputer. Library Python yang penting dalam pembuatan perangkat lunak akuisisi data ini yaitu Pyserial. Package pyserial terlebih dahulu diinstal agar dapat digunakan. Pyserial merupakan library yang digunakan untuk komunikasi serial Arduino. Pyserial memungkinkan pembacaan baris data tegangan keluaran sensor setiap waktu yang dihasilkan melalui komunikasi serial Arduino sehingga data ini dapat disimpan kemudian dapat diolah dan dianalisa.

Penulisan kode Python untuk akuisisi data ini menggunakan sublime-text yang merupakan salah satu perangkat lunak text editor. Kode Python yang ditulis pada perangkat lunak ini disimpan dalam file berekstensi *.py. File ini kemudian dijalankan pada CMD (command prompt) yang merupakan terminal pada sistem operasi window. Gambar 3 menjelaskan proses pengambilan data menggunakan perangkat lunak akuisisi data berbasis Python. Python dapat mengambil dan menyimpan data secara otomatis ke memori laptop dalam format *.xlsx sehingga dapat dibaca oleh Microsoft Excel.

\subsection{Persiapan Sampel}

Sampel yang digunakan adalah buah yang diambil dari Tandan Buah Segar (TBS) kelapa 
sawit dari perkebunan rakyat. TBS yang digunakan berjumlah 9 tandan yang terbagi dalam 3 kategori tingkat kematangan, setiap kategori terdiri dari 3 TBS. Tingkat kematangan TBS awal ditentukan secara tradisional oleh pemanen berpengalaman yaitu kategori mentah (Fraksi 0 dan 1), masak atau matang (fraksi 2 dan 3), serta lewat matang (fraksi 4). Setiap TBS dibagi menjadi 3 bagian yaitu ujung, tengah dan pangkal. Pada setiap bagian tersebut, 9 buah kelapa sawit yang berdekatan dilepaskan, dengan rincian 6 buah dikupas dan dijadikan sampel untuk pengukuran dengan sistem hidung elektronik dan 3 buah untuk uji kekerasan buah menggunakan penetrometer. Jumlah sampel dari setiap TBS adalah 27 buah yang berasal dari 3 bagian yang terdiri dari 18 buah untuk dikupas dan dimasukkan ke dalam ruang sampel. Pengukuran mengggunakan sistem hidung elektronik dilakukan 3 kali untuk setiap TBS yaitu menggunakan 6 buah kelapa sawit dari setiap bagian TBS tersebut. Pengukuran mengunakan hidung elektronik dan penetrometer dilakukan dalam waktu 24 jam setelah TBS di panen.

\subsection{Akuisisi Data}

Respon sensor terhadap aroma TBS kelapa sawit yang telah dikupas berupa tegangan keluaran sensor terhadap waktu diukur. Tegangan keluaran sensor ini diukur tiap satuan waktu melalui pembacaan nilai tegangan pada pin analog Arduino. Sebelum akuisisi data respons sensor terhadap aroma sampel dikerjakan, beberapa hal perlu dilakukan yaitu pembersihan ruang sensor, pemanasan sensor untuk memastikan bahwa larik sensor gas dapat digunakan untuk mendeteksi sampel, memastikan nilai tegangan dan arus yang diberikan sumber tegangan dari luar (catu daya) sudah stabil. Validasi dilakukan dengan mengambil data tanpa aroma sampel dan dengan aroma sampel buah sawit. Kemudian, pembersihan dan pemanasan sensor dilakukan pada udara bersih untuk menghilangkan bau atau aroma yang masih tertinggal pada sensor saat melakukan pengukuran sebelumnya sehingga dapat menghasilkan nilai awal yang stabil (Lelono dan Chairiawan, 2013).

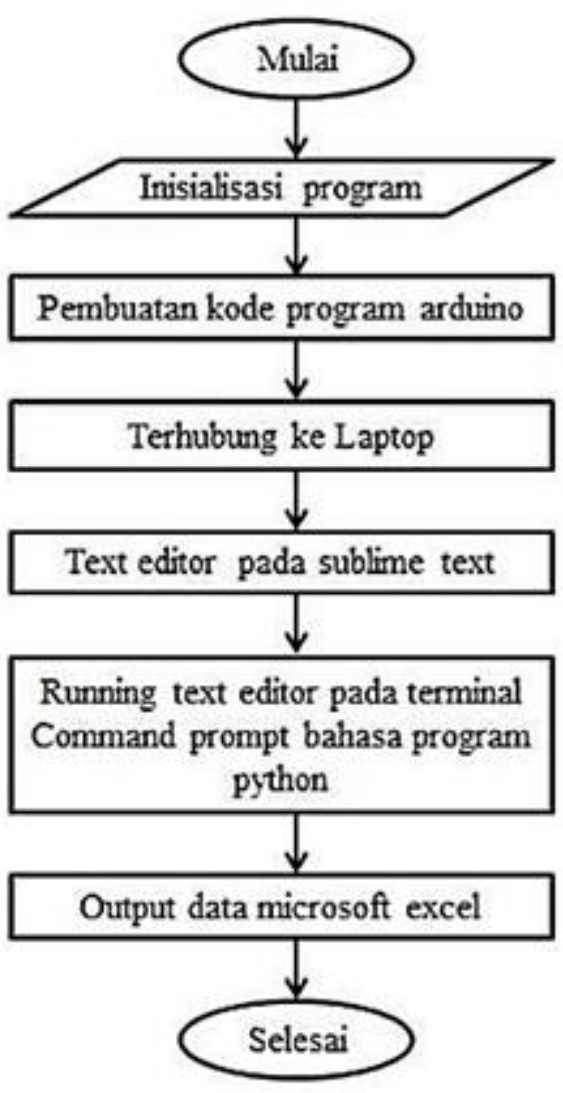

Gambar 3. Flowchart Akuisisi Data 
Proses akuisisi data terdiri dari tiga tahap yaitu flushing, collecting, dan purging. Pada masingmasing tahap ini akuisisi data tegangan terhadap waktu dilakukan selama 1 menit dengan perioda pembacaan nilai tegangan setiap 0.5 detik sehingga diperoleh 120 data tegangan terhadap waktu. Akuisisi data diawali dengan akuisisi data tegangan pada udara bersih yang disebut dengan tahap flushing. Selanjutnya tahap collecting yaitu akuisisi data tegangan sampel yang telah dimasukkan ke ruang sampel, selanjutnya gas dari ruang sampel dipompa melewati selang memasuki ruang sensor. Tahap terakhir yaitu purging dimana akuisisi data tegangan pada saat gas dari buah kelapa sawit pada ruang sensor dikeluarkan dan ruang sensor dibersihkan. Proses akuisisi data ini dilakukan 3 kali untuk setiap sampel dari tiga bagian TBS kelapa sawit agar diperoleh data pengukuran yang akurat.

\subsection{Pengukuran Kekerasan Buah}

Pengukuran nilai kekerasan buah kelapa sawit dilakukan secara manual menggunakan sebuah penetrometer manual untuk buah, model FP003 dengan range $1-24 \mathrm{~kg} / \mathrm{cm}^{2}$ dan resolusi $0,2 \mathrm{~kg} /$ $\mathrm{cm}^{2}$. Pengukuran tingkat kekerasan buah dilakukan untuk memvalidasi tingkat kematangan yang sebelumnya dikategorikan oleh pemanen berdasarkan perubahan warna dan fraksi (Sari et al, 2019). Cara pengukuran ini dilakukan dengan mengambil atau melepas bagian buah kelapa sawit. bagian exocarp buah diiris tipis dengan lebar lebih kurang 0.5-1 $\mathrm{cm}$. Penetrometer terlebih dulu diletakkan pada sebuah penyangga yang konstan, kemudian diposisikan tegak lurus pada bagian permukaan sampel yang telah diiris. Selanjutnya penetrometer ditekan tegak lurus terhadap sampel selama 2 detik. Nilai tingkat kekerasan akan terbaca pada skala penetrometer dalam satuan $\mathrm{kg} / \mathrm{cm}^{2}$. Pengukuran diulang tiga kali pada tempat yang berbeda untuk setiap buah, hasil akhir merupakan nilai kekerasan rata-rata. Tingkat kekerasan setiap TBS merupakan nilai rata-rata dari sampel buah dari ketiga bagian TBS.

\subsection{Pengolahan Data}

Pengolahan data meliputi pengolahan data respon sensor dan data tingkat kekerasan buah kelapa sawit. Data respon sensor yang berupa kurva tegangan keluaran sensor terhadap waktu diwakili oleh luasan trapezoid yang merupakan integrasi numerik dari fungsi tegangan terhadap waktu masing-masing sensor gas. Perhitungan luas trapezoid dilakukan secara komputasi mengunakan persamaan Newton-Cotes dengan aturan trapezoid $(\mathrm{n}=2)$ (Kiusalaas, 2006).

$$
\begin{gathered}
I=\int_{a}^{b} f(x) d x=\frac{h}{2}[f(a)-f(b)]+o\left(h^{3}\right) \\
I=\int_{a}^{b} f(x) d x=\sum_{i=0}^{N-1} \frac{h}{2}\left(f_{i}+f_{i+1}\right) \\
I=\frac{h}{2}\left(f_{0}+2 f_{1}+2 f_{2}+\cdots+2 f_{N-1}+f_{N}\right) \\
I=\int_{a}^{b} f(x) d x=\frac{h}{2}\left(f_{0}+\left(2 \sum_{i=1}^{N-1} f_{i}\right)+f_{N}\right)
\end{gathered}
$$

Perhitungan luas trapezoid tersebut dilakukan menggunakan program pengolahan data berbasis Python. Seluruh data tegangan terhadap waktu hasil pengukuran respon sensor terhadap aroma kelapa sawit dikumpulkan dalam bentuk file excel. Satu persatu file excel ini menggunakan algoritma perulangan (looping) dibaca oleh program Python kemudian dilakukan perhitungan luasan trapezoid masing-masing sensor. Data hasil perhitungan luasan trapezoid ini disimpan dalam berkas excel agar dapat diolah lebih lanjut. Grafik pola radar dibuat untuk mempermudah analisa data. Grafik hubungan luasan trapezoid tegangan setiap sensor terhadap nilai kekerasan TBS kelapa sawit dibuat untuk menganalisa nilai korelasi kedua besaran ini.

\section{HASIL DAN PEMBAHASAN}

Penelitian ini bertujuan untuk membangun dan menggunakan sistem hidung elektronik pada aroma sampel buah kelapa sawit dengan variasi tingkat kematangan (mentah, matang dan lewat matang). Tegangan keluaran sensor bergantung waktu diperoleh untuk setiap sensor secara otomatis mengunakan mikrokontroler Arduino dan program akuisisi data berbasis bahasa Python. Selanjutnya luas trapezoid dari fungsi tegangan terhadap waktu dihitung dan dihubungkan dengan tingkat kekerasan buah kelapa sawit.

\subsection{Hasil Rancangan Sistem Hidung Elektronik}

Hasil rancangan sistem hidung elektronik diperlihatkan pada Gambar 4. Larik sensor dan Arduino disusun dalam kotak akrilik yang terbagi 
dalam dua bagian, dengan rangkaian larik sensor gas, sensor suhu dan kelembaban berada di bagian atas dengan penambahan kipas yang melekat pada bagian atas yang berfungsi untuk penyebaran aroma agar mengenai semua sensor secara merata. Sensor suhu dan kelembaban digunakan agar dapat mengatur dan menstabilkan suhu ruang larik sensor. Selang oksigen digunakan sebagai saluran gas dari aroma sampel menuju larik sensor. Kotak akrilik dibuat tertutup agar kedap udara.

\subsection{Hubungan Kekerasan Buah dan Tingkat kematangan}

Gambar 5 memperlihatkan hubungan antara nilai kekerasan buah dan tingkat kematangan yang telah dikategorikan sebelumnya saat panen berdasarkan perubahan warna buah dan fraksi kematangan. Pada Gambar 5, buah dengan tingkat kematangan kategori mentah mempunyai nilai rata-rata kekerasan tertinggi yaitu $23.79 \mathrm{~kg} / \mathrm{cm}^{2}$, sedangkan buah dengan kategori lewat matang mempunyai tingkat kekerasan terendah yaitu $8.37 \mathrm{~kg} / \mathrm{cm}^{2}$. Nilai ini sedikit lebih besar dibanding penelitian sebelumnya untuk tingkat kekerasan buah sawit menggunakan alat yang sama namun mengunakan Tip penetrometer dengan range 0,5 $-15 \mathrm{~kg} / \mathrm{cm}^{2}$ dan resolusi $0,1 \mathrm{~kg} / \mathrm{cm}^{2}$ (Ishak et al., 2019). Nilai tingkat kekerasan semakin kecil seiring meningkatnya proses kematangan buah kelapa sawit Hal ini dipengaruhi oleh kandungan minyak pada sawit yang meningkat seiring proses kematangannya (Nualwijit dan Lerslerwong, 2014; Prada et al., 2011).

\subsection{Hubungan Aroma Buah dan Tingkat Kematangan}

Gambar 6 memperlihatkan hubungan antara luasan trapezoid yang mewakili tegangan yang dihasilkan oleh semua sensor. Nilai luasan trapezoid ini merupakan hasil rata-rata luasan trapezoid dari tegangan luaran setiap sensor untuk setiap TBS, dimana setiap TBS, tiga pengukuran dilakukan tehadap sampel-sampel buah dari tiga bagian TBS. Gambar 6 memperlihatkan bahwa semakin bertambah tingkat kematangan, nilai tegangan yang dihasilkan bertambah, ini menandakan bahwa komponen volatil dari asam palmitat dan asan

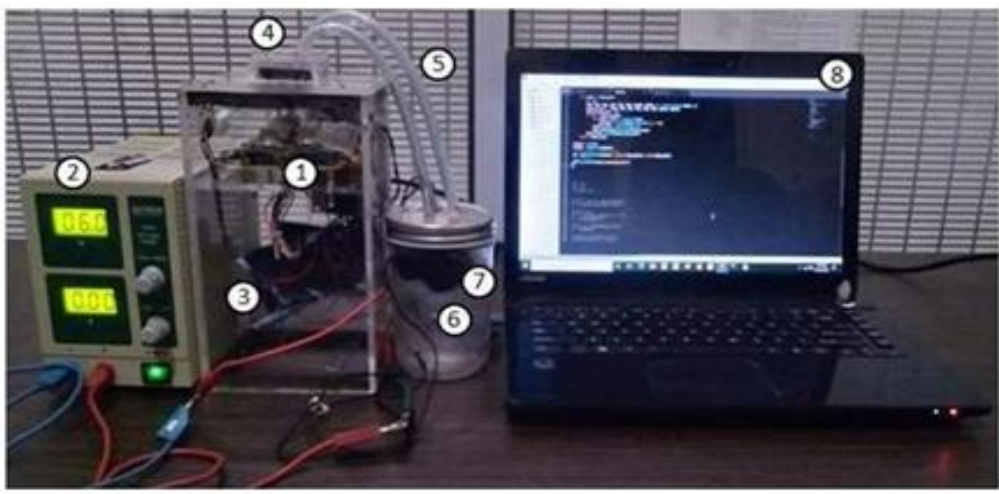

Keterangan :

1. Larik Sensor;

2. Catu daya;

3. Arduino;

4. Kipas;

5. Selang;

6. Wadah/chamber sampel;

7. Pompa;

8. Laptop.

Gambar 4. Sistem Hidung Elektronik yang Telah Dibangun

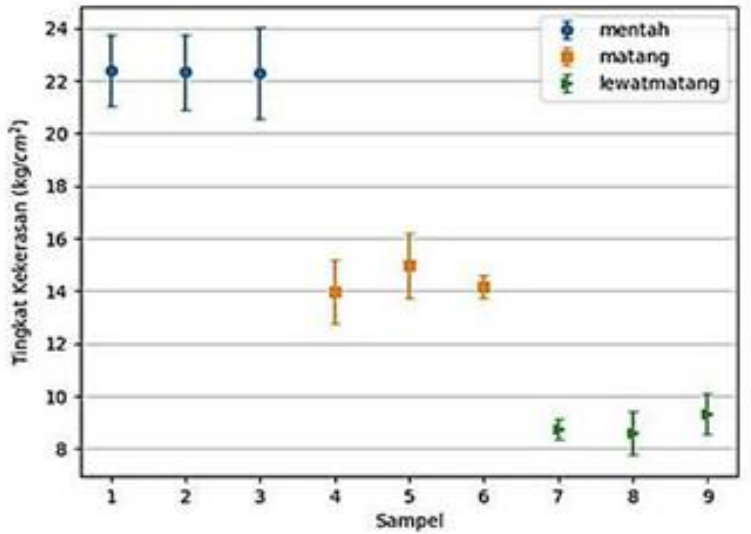

Gambar 5. Tingkat Kekerasan untuk Tiga Kategori Kematangan TBS 
oleat yang terkandung dalam asam lemak (fatty acids-FA) meningkat (Dussert et al., 2013). Menurut Prada et al (2011), buah sawit mengalami perubahan sifat fisika dan kimia selama proses pematangan di dalam TBS. Dari evaluasi proses pematangan dalam hitungan minggu dari penyerbukan, kandungan minyak mulai bertambah dengan cepat pada minggu ke 16, dan mencapai maksimum pada minggu ke 22 yaitu 55\% dalam mesocarp segar, dan $47 \%$ dalam keseluruhan buah kelapa sawit segar. Pada Gambar 6, luasan trapezoid pada buah mentah dan pada buah matang tidak sama untuk ketiga sampel TBS, ini dapat disebabkan karena kategori tingkat kematangan mentah secara tradisional terdiri dari fraksi F0 (sangat mentah) dan F1 (kurang matang atau mengkal). Ini juga berlaku untuk kategori tingkat kematangan "matang" yang terdiri dari dua fraksi yaitu F2 dan F3 yang kadar minyaknya sedikit berbeda.

\subsection{Hubungan Aroma Buah dan Tingkat Kekerasan}

Gambar 7 menunjukkan grafik hubungan luasan trapezoid untuk ke sembilan sampel TBS dengan 3 tingkat kematangan terhadap kekerasan buah TBS kelapa sawit untuk sensor MQ2 dam MQ135. Hubungan ini dibuat untuk menentukan nilai koefisien korelasi tegangan setiap respon sensor terhadap tingkat kekerasan buah. Koefisien korelasi yang dihasilkan adalah negatif yang menunjukkan bahwa hubungan kekerasan berbanding terbalik terhadap luasan trapezoid yang diperoleh dari masing-masing sensor, dimana luasan trapezoid semakin tinggi apabila tingkat kekerasan semakin rendah dan sebaliknya. Sensor MQ2 mempunyai koefisien determinasi $\mathrm{R}^{2}=0,78$ dan sensor MQ135 mempunyai $\mathrm{R}^{2}=0,54$.

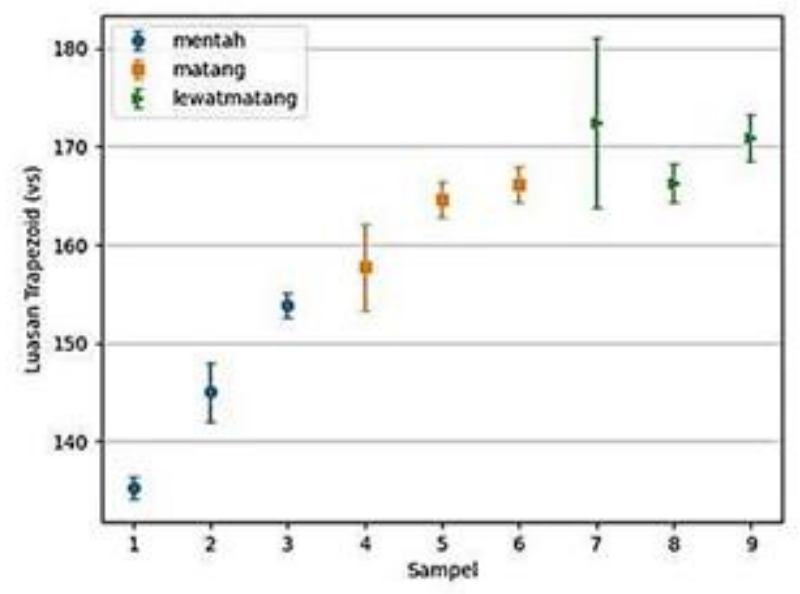

Gambar 6. Luasan Trapezoid untuk Tiga Kategori Kematangan TBS

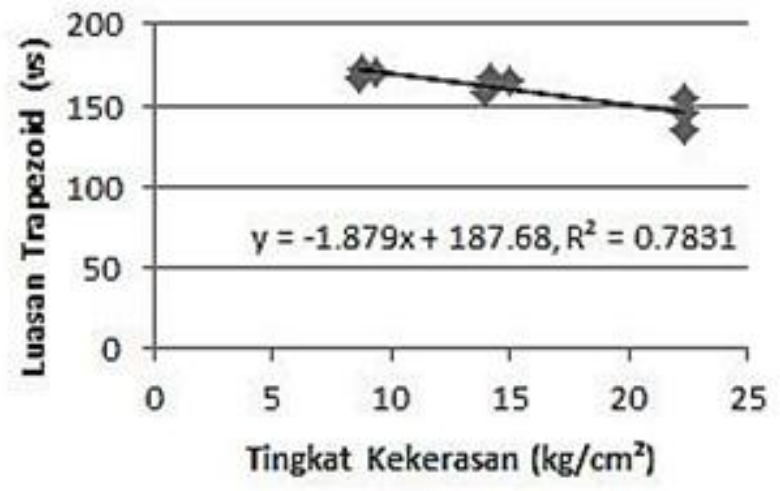

a

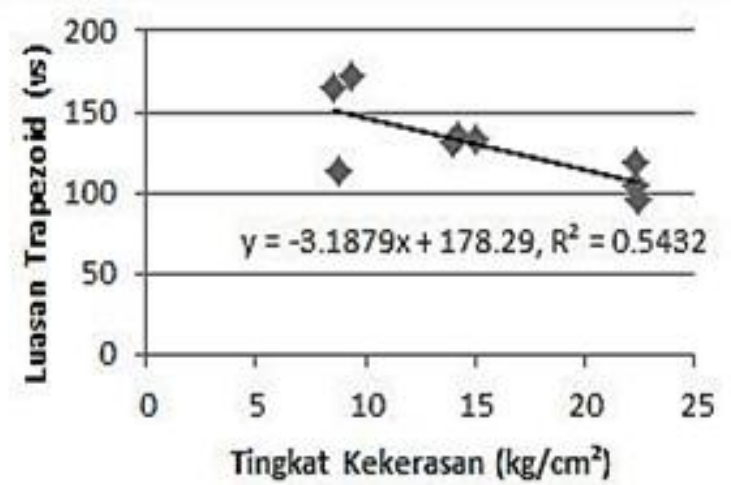

b

Gambar 7. Hubungan Luas Trapezoid dan Tingkat Kekerasan Buah pada Sensor (a) MQ2 dan

(b) MQ135 
Tingkat kekerasan buah berhubungan dengan tingkat kematangan buah kelapa sawit. Nilai luasan yang tinggi disebabkan kosentrasi gas volatil yang semakin besar. Menurut Prada et al (2011), mesocarp dari buah kelapa sawit mempunya komposisi kimia seperti asam lemak (FA) dan triacylglycerol (TAG) dan lipid yang terdiri dari karoten dan tocol. Asam lemak jenuh ini mengandung asam palmitat dan oleat. Kosentrasi kedua jenis asam ini berubah seiring berubahnya kosentrasi FA dan lipid dengan bertambahnya tingkat kematangan.

\subsection{Sensitivitas Sensor terhadap Aroma Buah Kelapa Sawit}

Hasil pengukuran luasan trapezoid untuk setiap sensor dan setiap TBS dengan tiga tingkat kematangan digambarkan dan bentuk Pola Radar seperti pada Gambar 8. Setiap tingkat kematangan ada 3 TBS sehingga diperoleh 9 titik data luasan trapezoid rata-rata seperti Tabel 2 . Luasan trapezoid terkecil dari semua sensor adalah pada TBS mentah sebesar 79,57 Vs oleh sensor MQ4, dan yang terbesar oleh sensor MQ3 pada TBS lewat matang yaitu 200,02 Vs. Gambar 8 menunjukkan bahwa setiap kematangan memiliki persentase komponen volatil yang berubah seiring meningkatnya kematangan buah kelapa sawit. Pola tingkat kematangan mentah lebih kecil dari pola untuk keadaan matang dan lewat matang.

Berdasarkan luas trapezoid yang diperoleh setiap sensor pada tiga tingkat kematangan, sensor MQ3 memberikan respon tertinggi diikuti oleh sensor MQ2, keduanya mempunyai kesamaan

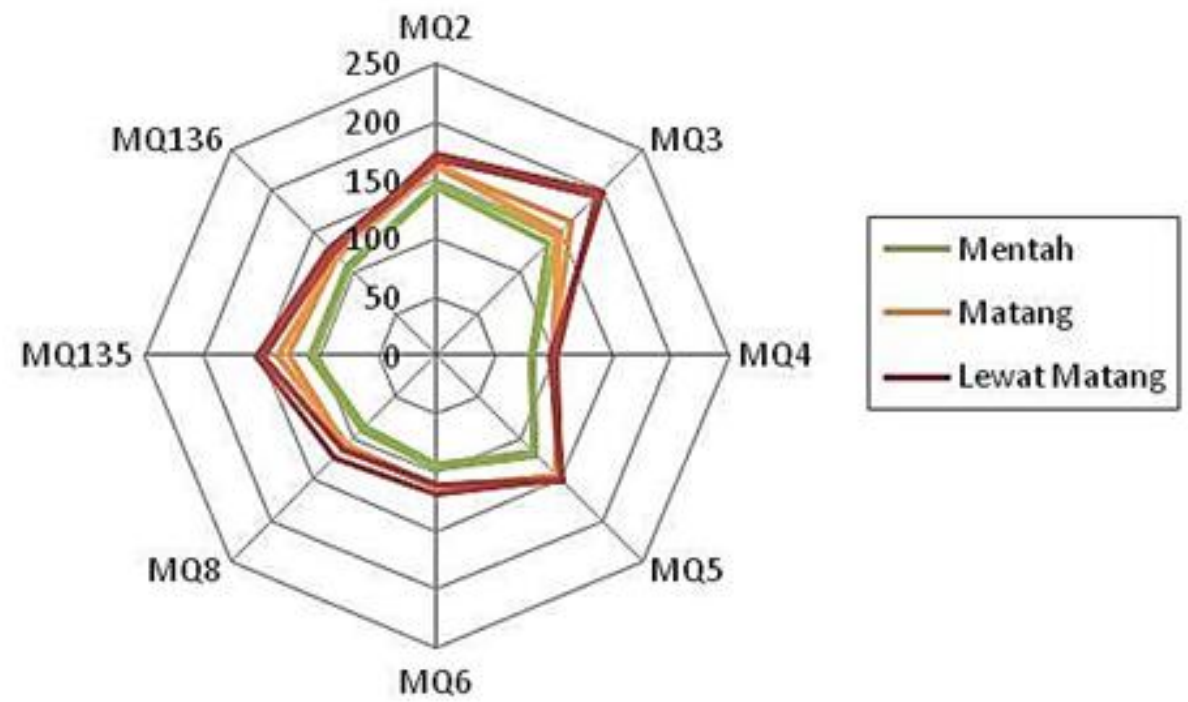

Gambar 8. Pola Radar Luasan Trapezoid Setiap Sensor

Tabel 2. Nilai Luas Trapezoid Setiap Sensor pada Tiga Tingkat Kematangan

\begin{tabular}{ccccccccc}
\hline Kematangan & $\begin{array}{c}\text { MQ2 } \\
\text { (Vs) }\end{array}$ & $\begin{array}{c}\text { MQ3 } \\
\text { (Vs) }\end{array}$ & $\begin{array}{c}\text { MQ4 } \\
\text { (Vs) }\end{array}$ & $\begin{array}{c}\text { MQ5 } \\
\text { (Vs) }\end{array}$ & $\begin{array}{c}\text { MQ6 } \\
\text { (Vs) }\end{array}$ & $\begin{array}{c}\text { MQ8 } \\
\text { (Vs) }\end{array}$ & $\begin{array}{c}\text { MQ135 } \\
\text { (Vs) }\end{array}$ & $\begin{array}{c}\text { MQ136 } \\
\text { (Vs) }\end{array}$ \\
\hline Mentah & 143,19 & 135,59 & 80,50 & 119,46 & 94,62 & 87,69 & 105,26 & 105,55 \\
Mentah & 144,34 & 146,60 & 79,57 & 116,82 & 93,03 & 87,00 & 104,89 & 106,74 \\
Mentah & 146,71 & 145,02 & 82,39 & 119,99 & 96,28 & 89,80 & 109,57 & 109,48 \\
Matang & 165,06 & 143,44 & 100,57 & 143,51 & 113,03 & 108,68 & 136,40 & 121,43 \\
Matang & 161,39 & 162,63 & 99,15 & 146,81 & 112,42 & 108,89 & 135,48 & 120,83 \\
Matang & 162,03 & 150,83 & 100,28 & 147,01 & 113,36 & 110,23 & 127,25 & 119,84 \\
Lewat Matang & 173,12 & 200,02 & 96,65 & 151,34 & 111,03 & 112,72 & 147,99 & 125,77 \\
Lewat Matang & 167,69 & 197,89 & 98,41 & 150,10 & 111,43 & 113,91 & 148,99 & 125,16 \\
Lewat Matang & 168,72 & 192,19 & 102,02 & 148,08 & 117,84 & 123,18 & 153,00 & 128,83 \\
\hline Rata-rata & $\mathbf{1 5 9 , 1 4}$ & $\mathbf{1 6 3 , 8 0}$ & $\mathbf{9 3 , 2 8}$ & $\mathbf{1 3 8 , 1 2}$ & $\mathbf{1 0 7 , 0 0}$ & $\mathbf{1 0 4 , 6 8}$ & $\mathbf{1 2 9 , 8 7}$ & $\mathbf{1 1 8 , 1 8}$ \\
\hline
\end{tabular}


dalam jenis gas yang dapat dideteksi, yaitu senyawa organic volatile (VOC) sehingga menghasilkan tegangan lebih tinggi dari yang lain, namun MQ3 lebih tinggi karena juga peka pada senyawa alkohol. Sensor MQ5 dan MQ135 memberi respon yang cukup tinggi. Sensor MQ5 mempunyai kesamaan dengan sensor MQ2 dan MQ3 yaitu dapat mendeteksi gas metana seperti ditunjukkan oleh Tabel 1. Sedangkan sensor MQ135 peka pada senyawa alkohol. Dengan demikian, selain senyawa VOC, gas metana dan alkohol merupakan komponen lainnya yang dapat diteliti lebih lanjut mengunakan Gas Chromatography-Mass Spectroscopy sehingga diperoleh komponen volatil yang terkandung pada buah kelapa sawit. Dari Tabel 2 dan Pola Radar, kombinasi sensor terbaik untuk deteksi kematangan adalah sensor MQ3, MQ5, dan MQ135. Sensor MQ135 dapat memisahkan antara ketiga tingkat kematangan dengan jelas, sedangkan sensor MQ3 dan MQ5 hanya dapat memisahkan antara dua tingkat yaitu mentah dan matang, dimana matang dan lewat matang mempunyai luas trapezoid yang hampir sama.

Menurut Kuntom et al (1989), Crude Palm Oil (CPO) maupun minyak sawit yang teroksidasi mengandung senyawa-senyawa volatil yang menyebabkan aroma pada minyak sawit. Volatil dari CPO yang didistilasi antara lain seperti 2,2,6tri m e thylc y clo-h ex a n o n e , $3,3,5$ trimethylcyclohex-2-enone, 2-nonanone, nnonanal, ethyl benzoate, linalol, trans-alloocimene, $\beta$-cyclocitral dan ionol. Volatil yang berhubungan dengan aroma dari minyak sawit yang segar dan berbau seperti kacang (nutty) disebabkan oleh 3,3,5-Trimethylcyclo-hexanone, sementara berbau seperti lemon, hijau daun (green), kacang-kacangan (nutty) disebabkan oleh $\beta$-cyclocitral dan ionol.

\section{KESIMPULAN}

Penelitian rancang bangun sistem hidung elektronik untuk mengkarakterisasi tingkat kematangan buah kelapa sawit telah dilakukan. Sistem ini menggunakan 8 sensor gas seri MQ yang berbentuk modul sensor. Luasan trapezoid dari kurva tegangan keluaran setiap sensor mewakili respon sensor terhadap tingkat kematangan buah. Luasan trapezoid yang tertinggi terdapat pada sensor MQ3 untuk kategori lewat matang senilai 200,02 Vs, dan terendah terdapat pada sensor MQ4 untuk kategori mentah senilai 79,57 Vs. Tingkat kekerasan buah kelapa sawit tertinggi adalah $23.79 \mathrm{~kg} / \mathrm{cm} 2$ yaitu untuk kategori mentah dan terendah $8.37 \mathrm{~kg} / \mathrm{cm} 2$ untuk buah lewat matang. Hasil ini telah sesuai dengan kategori tingkat kematangan secara tradisional. Grafik hubungan luasan trapezoid dan tingkat kekerasan buah memperlihatkan bahwa koefisien determinasi tertinggi adalah $\mathrm{R}^{2}=0,78$ pada sensor $\mathrm{MQ2}$ dan $\mathrm{R}^{2}=0,54$ untuk sensor MQ135. Hasil luasan trapezoid menunjukkan bahwa sensor MQ3, MQ5, dan MQ135 merupakan kombinasi sensor terbaik dari sistem hidung elektronik untuk buah kelapa sawit ini. Dengan optimasi pada perangkat lunak dan miniaturisasi pada perangkat kerasnya, hidung elektronik ini potensial digunakan pada penentuan umur panen TBS dan dapat diintegrasikan pada mesin sortir TBS setelah panen.

\section{UCAPAN TERIMA KASIH}

Penelitian ini dibiayai dan ditanggung penuh dari dana penelitian LPPM Universitas Riau dengan nomor kontrak 822/2020.

\section{DAFTAR PUSTAKA}

Adak, M.F. dan Yumusak, N. 2016. Classification of E-nose aroma data of four fruit types by ABC-based neural network. Sensors, 16(3): 304 (13 halaman). DOI: 10.3390/ s16030304

Baietto, M., dan Wilson, A.D. 2015. Electronicnose applications for fruit identification, ripeness and quality grading. Sensors, 15(1): 899-931. DOI: 10.3390/ s150100899.

Chen, L.Y., Wu, C.C., Chou, T.I., Chiu, S.W., dan Tang, K.T. 2018. Development of a dual MOS electronic nose/camera system for improving fruit ripeness classification. Sensors, 18(10): 3256 (11 halaman). DOI: $10.3390 / \mathrm{s} 18103256$ 
Dussert, S., Guerin, C., Andersson, M., Joët, T., Tranbarger, T.J., Pizot, M., Sarah, G., Omore, A., Durand-Gasselin, T., dan Morcillo, F. 2013. Comparative transcriptome analysis of three oil palm fruit and seed tissues that differ in oil content and fatty acid composition. Plant Physiology, 162(3): 1337-1358. DOI: $10.1104 / p p .113 .220525$

Fadilah, N., dan Saleh, J. M. 2014. Color Feature extraction of oil palm fresh fruit bunch image for ripeness classification. Applied Computational Science (Proceedings of the 13th International Conference on Applied Computer and Applied Computational Science, ACACOS '14), Kuala Lumpur, Malaysia, April 23-25, 2014: 51-55.

Hudori, M. 2016. Dampak kerugian dan usulan pemecahan masalah kualitas crude palm oil (CPO) di pabrik kelapa sawit. Malikussaleh Industrial Engineering Journal, 5(1): 4045.

Huang, L., Meng, L., Zhu, N., dan Wu, D. 2017. A primary study on forecasting the days before decay of peach fruit using nearinfrared spectroscopy and electronic nose techniques', Postharvest Biology and Technology, 133: 104-112. DOI: 10.1016/ j.postharvbio.2017.07.014.

Ishak, H., Shiddiq, M., Fitra, R. H., dan Yasmin, N. Z. 2019. Ripeness level classification of oil palm fresh fruit bunch using laser induced fluorescence imaging. Journal of Aceh Physics Society, 8(3): 84-89. DOI: 10.24815/jacps.v8i3.14139.

Kiusalaas, J. 2005. Numerical Methods in Engineering with MATLAB. Cambridge University Press, Cambridge, UK: 426 halaman.

Koushki, M., Nahidi, M., Cheraghali, F. 2015. Physico-chemical properties, fatty acid profile and nutrition in palm oil. Archives of Advances in Biosciences, 6(3): 117-134.

Kuntom, A.H.J., Dirinck, P.J., dan Schamp, N.M. 1989. Identification of volatile compounds that contribute to the aroma of fresh palm oil and oxidized oil. Journal of Oil Palm Research, 1(1): 53-61.

Lelono, D., dan Chairiawan, M.A. 2013. Karakterisasi pola aroma salak pondoh dengan e-nose berbasis sensor metal oksida. Indonesian Journal of Electronics and Instrumentation Systems (IJEIS), 3(1): 71-82.

Nualwijit, N., dan Lerslerwong L. 2014. Post harvest ripening of oil palm fruit is accelerated by application of exogenous ethylene. Songklanakarin Journal of Science and Technology, 36(3): 255-259.

Prada, F., Ayala-Diaz, I.M., Delgado, W., RuizRomero, R., dan Romero, H.M. 2011. Effect of fruit ripening on content and chemical composition of oil from three oil palm cultivars (Elaeis guineensis Jacq.) grown in Colombia. Journal of Agricultural and Food Chemistry, 59(18): 10136-42. DOI: 10.1021/jf201999d

Razali, M.H., Halim, A.S.M.A., dan Roslan, S. 2012. A review on crop plant production and ripeness forecasting. Journal IJACS, 4(2): 54-63.

Sari, N., Shiddiq, M., Fitra, R.H., dan Yasmin, N.Z. 2019. Ripeness classification of oil palm fresh fruit bunch using an optical probe. Journal of Aceh Physics Society, 8(3): 7277. DOI: $10.24815 /$ jacps.v8i3.14122.

Song, J., Bi, J., Chen, Q., Wu, X., Lyu, Y., dan Meng, C. 2019. Assessment of sugar content, fatty acids, free amino acids, and volatile profiles in jujube fruits at different ripening stages. Food Chemistry, 270: 344-352.

Sunilkumar, K., Babu, D.S. 2013. Surface color based prediction of oil content in oil palm (Elaeis guineensis jacq.) fresh fruit bunch. African Journal of Agricultural Research, 8: 564-569.

Suwannarat, S., Khaorapapong, T., Chongcheawchamnan, M. 2012. Prediction of oil content in fresh palm fruit based on an ultrasonic technique. 
Kasetsart Journal - Natural Science, 46(2): 318-324.

Utom, S.L, Mohamad, E.J, Mohmad Ameran, H.L., Kadir, H.A., Muji, S.Z.M., Rahim, R.A., dan Pusppanathan, J. 2018. Non-destructive oil palm fresh fruit bunch (ffb) grading technique using optical sensor. International Journal of Integrated Engineering, 10(1): 35-39.

Yeow, Y. K., Abbas, Z., Khalid, K. 2010. Application of microwave moisture sensor for determination of oil palm fruit ripeness. Measurement Science Review, 10(1): 7-14. DOI: 10.2478/v10048-010-0002-x.
Zakaria, A., Md Shakaff, A.Y., Masnan, M.J., Saad, F.S.A., Adom, A.H., Ahmad, M.N., Jaafar, M.N., Abdullah, A.H., Kamarudin, L.M. 2012. Improved maturity and ripeness classifications of Magnifera Indica cv. harumanis mangoes through sensor fusion of an electronic nose and acoustic sensor. Sensors, 12(5): 6023-6048. DOI: 10.3390/ s120506023.

Zolfagharnassab, S., Mohamed, S. A. R., dan Ehsani, R. 2017. Emissivity determination of oil palm fresh fruit ripeness using a thermal imaging technique. Acta Horticulturae, 1152: 189-194. DOI: 10.17660/ActaHortic.2017.1152.26 